\title{
Factors Associated With Long-Term Survival in Gemcitabine-Concurrent Proton Radiotherapy For Non-Metastatic Locally Advanced Pancreatic Cancer: a Single-Center Retrospective Study
}

Yuta Ogura ( $\sim$ yutakobe@hotmail.co.jp )

Kobe University Hospital: Kobe Daigaku Igakubu Fuzoku Byoin

Kazuki Terashima

Hyogo Ion Beam Medical Center

Yoshihide Nanno

Kobe University Hospital: Kobe Daigaku Igakubu Fuzoku Byoin

SungChul Park

Hyogo Ion Beam Medical Center

Masaki Suga

Hyogo Ion Beam Medical Center

Daiki Takahashi

Hyogo Ion Beam Medical Center

Yoshiro Matsuo

Hyogo Ion Beam Medical Center

Nor Shazrina Sulaiman

Hyogo Ion Beam Medical Center

\section{Sunao Tokumaru}

Hyogo Ion Beam Medical Center

\section{Tomoaki Okimoto}

Hyogo Ion Beam Medical Center

Hirochika Toyama

Kobe University Hospital: Kobe Daigaku Igakubu Fuzoku Byoin https://orcid.org/0000-0003-0360-8460

Takumi Fukumoto

Kobe University Hospital: Kobe Daigaku Igakubu Fuzoku Byoin

\section{Research Article}

Keywords: pancreatic cancer, proton radiotherapy, gemcitabine, chemoradiotherapy, retrospective study, prognostic factor, long-term survival outcome 
Posted Date: November 15th, 2021

DOI: https://doi.org/10.21203/rs.3.rs-1065586/v1

License: (9) This work is licensed under a Creative Commons Attribution 4.0 International License. Read Full License

Version of Record: A version of this preprint was published at Radiation Oncology on February 10th, 2022. See the published version at https://doi.org/10.1186/s13014-022-02001-w. 


\section{Abstract}

Background: Factors associated with long-term survival in gemcitabine-concurrent proton radiotherapy (GPT) for non-metastatic locally advanced pancreatic cancer (LAPC) remain unclear. This study aimed to determine the factors associated with long-term survival in GPT for non-metastatic LAPC.

Methods: The medical records of 123 patients with LAPC treated with GPT between February 2009 and December 2019 at Hyogo Ion Beam Medical Center were retrospectively reviewed to assess the factors associated with long-term survival outcomes.

Results: The median survival time of the total cohort treated with GPT was 18.7 months. The 1- and 2year overall, local progression-free, and progression-free survival rates were $70.4 \%$ and $35.7 \%, 78.2 \%$ and $59.0 \%$, and $38.6 \%$ and $20.8 \%$, respectively. Multivariate analysis revealed that LAPCs at the pancreatic body-tail and those without anterior peripancreatic invasion were independently associated with longer overall survival ( $P=0.040$ and $P=0.015$, respectively). The median survival times of patients with LAPC at the pancreatic body-tail and those with LAPC without anterior peripancreatic invasion were 24.1 and 28.1 months, respectively. LAPCs at the pancreatic body-tail had a higher volume ratio irradiated over 60 Gy equivalents at gross tumor volume than those at the pancreatic head $(P<0.001)$. LAPCs with anterior peripancreatic invasion had more peritoneal recurrence within 6 months than those without anterior peripancreatic invasion $(P=0.039)$.

Conclusions: GPT is a promising treatment option for patients with LAPC at the pancreatic body-tail and those with LAPC without anterior peripancreatic invasion.

\section{Background}

Pancreatic cancer has a poor prognosis and is the fourth leading cause of cancer-related deaths in Western countries [1, 2]. Although radical surgical resection is the only potentially curative treatment, more than $30 \%$ of patients are diagnosed with unresectable pancreatic cancer due to extensive vascular involvement without distant metastasis (locally advanced pancreatic cancer [LAPC]) [3]. The standard treatment for LAPC is chemotherapy or chemoradiotherapy [4], and recent studies have shown that intensive chemotherapies, such as multiagent 5-fluorouracil, leucovorin, irinotecan, and oxaliplatin (FOLFIRINOX) and gemcitabine plus nab-paclitaxel (GnP), achieved long-term overall survival (OS) $[5,6]$. Other studies have reported that the combination of radiotherapy with chemotherapy improves local control and prolongs OS compared with chemotherapy alone [7, 8]. Since approximately $30-40 \%$ of patients with LAPC die of local progression without developing distant metastases $[9,10]$, chemoradiotherapy with high local tumor control could be a feasible treatment option for these patients.

Radiotherapy for pancreatic cancer remains challenging owing to its low radiosensitivity and the proximity of the pancreas to highly radiosensitive organs, such as the gastrointestinal (GI) tract. Recently, particle radiotherapy (PRT), such as proton or carbon ion therapy, has been increasingly used for the treatment of pancreatic cancer. PRT facilitates the selective irradiation of the tumor while reducing GI 
toxicity owing to the physical properties of the dose deposition, namely the Bragg peak [11-13]. Some studies have reported encouraging results of PRT for LAPC, including increased irradiation doses, improved local control, and prolonged OS [14-18]. However, patient backgrounds and treatment protocols varied among these studies; thus, it remains unclear which group of patients can achieve feasible outcomes with PRT.

We have previously reported the feasibility and efficacy of gemcitabine-concurrent proton radiotherapy (GPT) for LAPC in a previous phase I/II study [14]; subsequently, we have performed GPT on many patients with LAPC. This study identified its long-term outcomes in a large number of patients with LAPC treated with GPT, and assessed the factors associated with long-term survival outcomes of GPT for LAPC.

\section{Methods}

\section{Patients}

The medical records of patients with LAPC $(n=306)$ treated with GPT between February 2009 and December 2019 at Hyogo Ion Beam Medical Center were retrospectively reviewed. Of the 306 patients, 44 who received GPT with protocol doses other than 67.5 Gy equivalents (GyE) were excluded: 18, 20, and 6 patients received 50 GyE in 25 fractions, 52 GyE in 26 fractions, and 70.2 GyE in 26 fractions, respectively. Additionally, 139 patients who had received prior treatment for the primary tumor were excluded. In total, 123 patients treated with GPT of $67.5 \mathrm{GyE}$ in 25 fractions without prior treatment were enrolled in this study.

Abdominal contrast-enhanced computed tomography (CT), chest CT, and positron emission tomography with 18F-fluorodeoxyglucose (FDG-PET) were performed before GPT. The diagnosis of pancreatic cancer was confirmed histologically $(n=75)$ or clinically by diagnostic imaging, such as CT and/or magnetic resonance imaging and/or ultrasonic endoscopy $(n=48)$. LAPC was defined as tumor contact with the superior mesenteric artery or celiac artery $>180^{\circ}$ or unreconstructible superior mesenteric vein/portal vein due to tumor involvement or occlusion [19].

This study was approved by the Institutional Review Board of Hyogo lon Beam Medical Center and conducted according to the ethical standards stated in the 1964 Declaration of Helsinki and its later amendments; the need for informed consent was waived owing to the retrospective nature of the study.

\section{Proton radiotherapy}

The patients were treated with 150-210 MeV proton beams accelerated by a synchrotron following a linear accelerator (Hybrid Particle Therapy System; Hitachi Ltd., Tokyo, Japan), and a respiratory gating system was used to irradiate the beam during the exhalation phase. Patients were immobilized using a custom-made thermoplastic cast in the prone position, and the setup was performed daily before irradiation using bony landmarks and fiducial markers detained to a branch of the gastroduodenal and/or 
dorsal pancreatic artery by angiography. The treatment plans were developed using a 2-mm slice thickness CT-based three-dimensional treatment planning system (Mitsubishi Electric, Tokyo, Japan).

The gross tumor volume (GTV) was defined as the primary tumor and the apparent lymph nodes. The clinical target volume (CTV) comprised the addition of a 5-mm margin to the GTV, prophylactic irradiation regions containing the draining lymph nodes and para-aortic lymph nodes, and peripheral regions surrounding the celiac and superior mesenteric arteries. The planning target volume (PTV) was defined as the CTV with a 5-mm setup margin and a 1-5-mm respiratory gating margin, which was measured on CT images between inspiratory and expiratory phases. The total delivered doses were calculated according to the relative biological effectiveness (RBE), and the RBE value for the treatment beam was 1.1 [20]. Total doses of $67.5 \mathrm{GyE}$ in 25 daily fractions were administered using the field-in-field technique [14]. In general, the stomach, small bowel including the duodenum, kidneys, and spinal cord were defined as organs at risk. The dose restrictions for the stomach, duodenum, and spinal cord were approximately 50, 50 , and $45 \mathrm{GyE}$, respectively. Additionally, we planned the irradiated volumes of the stomach, duodenum, and kidneys to be as minimal as possible.

\section{Concurrent and adjuvant chemotherapy}

Concurrent chemotherapy was provided with gemcitabine monotherapy. All patients were scheduled to receive intravenous infusions of gemcitabine $\left(800 \mathrm{mg} / \mathrm{m}^{2}\right)$ for the initial 3 weeks (days 1,8 , and 15) during 5 weeks of proton radiotherapy [14]. Gemcitabine was administered with an absolute granulocyte count of $>2000 / \mathrm{mm}^{3}$ and a platelet count of $>70,000 / \mathrm{m}^{3}$ on the scheduled day.

Following GPT, 106 patients received systemic chemotherapy. Three patients did not receive adjuvant chemotherapy: one rejected the therapy, and two were excluded due to poor general condition. The details of the treatment were not available for the remaining 14 patients.

\section{Patient follow-up}

Patients were followed up at our outpatient clinic every 3 months after GPT. Blood examinations and contrast-enhanced CT and/or FDG-PET were performed at every visit. Endoscopic examinations were performed to evaluate radiation-related gastroduodenal complications.

Local progression was defined as tumor progression inside the PTV and diagnosed comprehensively based on the following findings: enlarged tumor size, increased FDG accumulation, and sustained increase in tumor markers for at least 3 months without any distant metastases. GPT toxicities were evaluated according to the National Cancer Institute Common Terminology Criteria for Adverse Events (version 4.0).

\section{Statistical analyses}

Patient characteristics are described as medians (ranges), while survival times and rates are described as medians (95\% confidence intervals [Cls]). To evaluate between-group differences, the $\chi^{2}$ test was used for 
categorical variables, and the Wilcoxon rank-sum test was used for continuous variables. The KaplanMeier method was used to estimate survival outcomes, such as OS, progression-free survival (PFS), and local PFS (LPFS), and the differences were evaluated using log-rank tests. These values were calculated from the initiation date of GPT. Univariate and multivariate analyses with Cox proportional hazard models were performed to determine the factors associated with OS. Variables with a $P$-value $<0.1$ in univariate analysis were included in the multivariate analysis, and those with a $P$-value $<0.05$ were considered statistically significant. All statistical analyses were performed using the JMP 16 statistical package (SAS Institute, Cary, NC, USA).

\section{Results}

\section{Patient characteristics}

The baseline patient characteristics are summarized in Table 1. We examined 58 women (47\%) and 65 men (53\%), with a median age of 64 years (range: 38-84). Moreover, $59(48 \%)$ and 64 (52\%) patients had pancreatic head and pancreatic body-tail cancers, respectively. The median tumor size was $32 \mathrm{~mm}$ (1168). On CT images obtained before irradiation, bile duct, duodenal, and anterior peripancreatic invasions were observed in 63 (51\%), 64 (52\%), and 104 (85\%) patients, respectively. Posterior peripancreatic, venous, arterial, and extrapancreatic nerve plexus invasions were observed in all patients. All patients received GPT of $67.5 \mathrm{GyE}$ in 25 fractions and completed the planned treatment. The median GTV volume

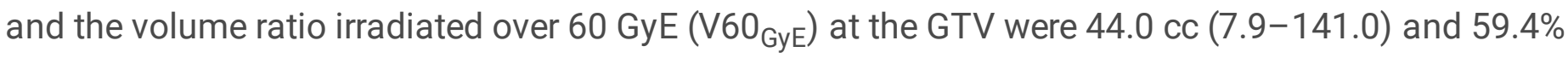
(6.2-99.7), respectively.

Table 1 Patient characteristics 


\begin{tabular}{|c|c|}
\hline Variables & Number of patients $(n=123)$ \\
\hline Median age, years (range) & $64(38-84)$ \\
\hline \multicolumn{2}{|l|}{ Gender, n (\%) } \\
\hline Male & $65(53)$ \\
\hline Female & $58(47)$ \\
\hline \multicolumn{2}{|l|}{ ECOG-PS, n (\%) } \\
\hline 0 & $94(76)$ \\
\hline 1 & $27(22)$ \\
\hline 2 & $2(2)$ \\
\hline \multicolumn{2}{|l|}{ Tumor location, n (\%) } \\
\hline Head & $59(48)$ \\
\hline Body-Tail & $64(52)$ \\
\hline Median CEA, ng/mL (range) & $3.3(0.7-70.1)$ \\
\hline Median CA19-9, U/mL (range) & $366.8(0.1-27600)$ \\
\hline \multicolumn{2}{|l|}{ Adjuvant therapy, n (\%) } \\
\hline Yes & $106(87)$ \\
\hline No & $3(2)$ \\
\hline Unknown & $14(11)$ \\
\hline \multicolumn{2}{|l|}{ Pathological diagnosis, n (\%) } \\
\hline Yes & $75(61)$ \\
\hline No & $48(39)$ \\
\hline Median tumor diameter, mm (range) & $32(11-68)$ \\
\hline \multicolumn{2}{|l|}{ Lymph node metastasis, n (\%) } \\
\hline Positive & $41(33)$ \\
\hline Negative & $82(67)$ \\
\hline \multicolumn{2}{|l|}{ Bile duct invasion, n (\%) } \\
\hline Positive & $63(51)$ \\
\hline Negative & $60(49)$ \\
\hline \multicolumn{2}{|l|}{ Duodenal invasion, $\mathrm{n}(\%)$} \\
\hline Positive & $64(52)$ \\
\hline
\end{tabular}


Anterior peripancreatic invasion, $\mathrm{n}(\%)$

Positive $104(85)$

Negative

Posterior peripancreatic invasion, $\mathrm{n}(\%)$

Positive $123(100)$

Negative

$0(0)$

Venous invasion, $\mathrm{n}(\%)$

Positive $123(100)$

Negative

$0(0)$

Arterial invasion, $\mathrm{n}(\%)$

Positive $123(100)$

Negative

$0(0)$

Extrapancreatic nerve plexus invasion, $\mathrm{n}(\%)$

Positive $123(100)$

Negative

$0(0)$

Median GTV volume, cc (range)

$44.0(7.9-141.0)$

Median CTV volume, cc (range) $186.5(85.0-420.6)$

Median GTV V60 ${ }_{\mathrm{GyE}}$ \% (range) $59.4(6.2-99.7)$

Median CTV V60 $0_{\mathrm{GyE}}$ \% (range) 59.3(25.6-86.7)

Abbreviations: ECOG-PS, Eastern Cooperative Oncology Group-Performance Status; CEA, carcinoembryonic antigen; CA19-9, carbohydrate antigen 19-9; GTV, gross tumor volume; CTV, clinical

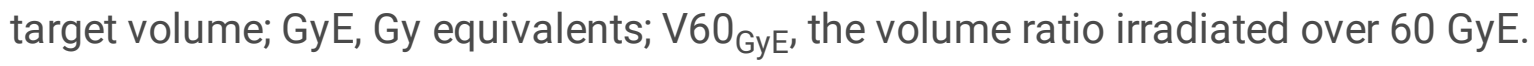

\section{Patient survival}

The median follow-up time was 15.2 months (4.4-89.2). The median survival time (MST) was 18.7 months (95\% Cl: 14.7-22.9). The 1- and 2-year OS rates were 70.4\% (62.6-79.2) and 35.7\% (27.7-46.0), respectively (Fig. 1a). The 1- and 2-year LPFS rates were 78.2\% (69.7-87.6) and 59.0\% (46.2-75.4), respectively (Fig. 1b). The 1- and 2-year PFS rates were 38.6\% (30.2-49.3) and 20.8\% (13.7-31.5), respectively (Fig. 1c). Local progression developed in 18 (15\%) patients, whereas distant metastases developed in 58 (47\%) patients within 1 year. In total, 74 (60\%) patients experienced distant metastases, 
including $36(29 \%)$ with liver metastasis, 30 (24\%) with peritoneal dissemination, and $15(12 \%)$ with lung metastasis.

\section{Toxicity}

Acute toxicities of grades 3 and 4 were observed in $52(42 \%)$ and 3 patients (2\%), respectively. All grade 3 and 4 toxicities were hematologic, including leukopenia, neutropenia, and thrombocytopenia in 55 (45\%), $28(23 \%)$, and 4 patients (3\%), respectively. There were no grade 5 acute toxicities or treatment-related deaths. Regarding late toxicities, $6(5 \%)$ patients experienced grade 3 toxicities comprising bile duct stenosis, duodenal stenosis, and gastric hemorrhage in $1(1 \%), 1(1 \%)$, and $4(3 \%)$ patients, respectively. Two (2\%) patients experienced grade 4 gastric hemorrhage. Three (2\%) patients experienced grade 5 toxicities including duodenal perforation and bile duct perforation with a metallic biliary stent in $1(1 \%)$ and $2(2 \%)$ patients, respectively.

\section{Prognostic factors}

Univariate analysis revealed that LAPCs at the pancreatic body-tail or those without bile duct, duodenal, or anterior peripancreatic invasions were associated with longer OS than those at the pancreatic head or those with bile duct, duodenal, or anterior peripancreatic invasions (Table 2). In multivariate analysis, LAPCs at the pancreatic body-tail (hazard ratio [HR]: $0.12,95 \% \mathrm{Cl}: 0.02-0.91, P=0.040$ ) and those without anterior peripancreatic invasion (HR: $0.46,95 \% \mathrm{Cl}: 0.25-0.86, P=0.015)$ were significantly associated with longer OS (Table 2). 
Table 2

Univariate and multivariate analyses of prognostic factors for overall survival

\begin{tabular}{|c|c|c|c|c|c|}
\hline & & Univariate & & Multivariate & \\
\hline Variables & $\mathrm{n}(\%)$ & $\mathrm{HR}(95 \% \mathrm{Cl})$ & $\begin{array}{l}P \\
\text { value }\end{array}$ & $\mathrm{HR}(95 \% \mathrm{Cl})$ & $\begin{array}{l}P \\
\text { value }\end{array}$ \\
\hline Age $\geqq 65$ years & $\begin{array}{l}57 \\
(46)\end{array}$ & $\begin{array}{l}1.47(0.97- \\
2.22)\end{array}$ & 0.069 & $\begin{array}{l}1.52(0.99- \\
2.33)\end{array}$ & 0.053 \\
\hline Gender, Male & $\begin{array}{l}65 \\
(53)\end{array}$ & $\begin{array}{l}0.82(0.55- \\
1.24)\end{array}$ & 0.351 & & \\
\hline ECOG-PS, 0 & $\begin{array}{l}94 \\
(76)\end{array}$ & $\begin{array}{l}0.93(0.59- \\
1.47)\end{array}$ & 0.744 & & \\
\hline Tumor location, Body-Tail & $\begin{array}{l}64 \\
(52)\end{array}$ & $\begin{array}{l}0.50(0.33- \\
0.76)\end{array}$ & 0.001 & $\begin{array}{l}0.12(0.02- \\
0.91)\end{array}$ & 0.040 \\
\hline $\mathrm{CEA} \geqq 5 \mathrm{ng} / \mathrm{mL}$ & $\begin{array}{l}34 \\
(28)\end{array}$ & $\begin{array}{l}1.27(0.82- \\
1.97)\end{array}$ & 0.291 & & \\
\hline $\mathrm{CA} 19-9 \geqq 37 \mathrm{U} / \mathrm{mL}$ & $\begin{array}{l}104 \\
(85)\end{array}$ & $\begin{array}{l}0.98(0.55- \\
1.74)\end{array}$ & 0.940 & & \\
\hline Pathological diagnosis, Yes & $\begin{array}{l}75 \\
(61)\end{array}$ & $\begin{array}{l}0.89(0.59- \\
1.35)\end{array}$ & 0.589 & & \\
\hline Lymph node metastasis, Negative & $\begin{array}{l}82 \\
(67)\end{array}$ & $\begin{array}{l}1.04(0.68- \\
1.60)\end{array}$ & 0.846 & & \\
\hline Bile duct invasion, Negative & $\begin{array}{l}60 \\
(49)\end{array}$ & $\begin{array}{l}0.61(0.40- \\
0.92)\end{array}$ & 0.018 & $\begin{array}{l}7.22(0.76- \\
68.4)\end{array}$ & 0.085 \\
\hline Duodenal invasion, Negative & $\begin{array}{l}59 \\
(48)\end{array}$ & $\begin{array}{l}0.57(0.38- \\
0.87)\end{array}$ & 0.009 & $\begin{array}{l}0.55(0.19- \\
1.63)\end{array}$ & 0.283 \\
\hline $\begin{array}{l}\text { Anterior peripancreatic invasion, } \\
\text { Negative }\end{array}$ & $\begin{array}{l}19 \\
(15)\end{array}$ & $\begin{array}{l}0.50(0.27- \\
0.92)\end{array}$ & 0.027 & $\begin{array}{l}0.46(0.25- \\
0.86)\end{array}$ & 0.015 \\
\hline GTV V60 $0_{G y E} \geqq 60 \%$ & $\begin{array}{l}59 \\
(48)\end{array}$ & $\begin{array}{l}0.77(0.51- \\
1.16)\end{array}$ & 0.208 & & \\
\hline \multicolumn{6}{|c|}{$\begin{array}{l}\text { Abbreviations: HR, hazard ratio; Cl, confidence interval; ECOG-PS, Eastern Cooperative Oncology } \\
\text { Group-Performance Status; CEA, carcinoembryonic antigen; CA19-9, carbohydrate antigen 19-9; GTV, } \\
\text { gross tumor volume; GyE, Gy equivalents; } \mathrm{V}_{\text {GyE }} \text {, the volume ratio irradiated over } 60 \mathrm{GyE} \text {. }\end{array}$} \\
\hline \multicolumn{6}{|c|}{ Significant $P$ values $(<0.05)$ are in bold. } \\
\hline
\end{tabular}

LAPCs at the pancreatic body-tail had a significantly longer MST than those at the pancreatic head (24.1 [18.8-30.2] vs. 14.0 [12.1-18.9] months, $P=0.001$; Fig. 2a). The median LPFS times of LAPCs at the pancreatic body-tail and pancreatic head were 40.1 (25.0-NA) and $36.6(16.1-\mathrm{NA})$ months, respectively 
$(P=0.052$, Fig. 2b). There was no significant difference between the PFS of the two groups. Table 3 presents the dose intensity based on the dose volume histogram differences between the groups. GTV

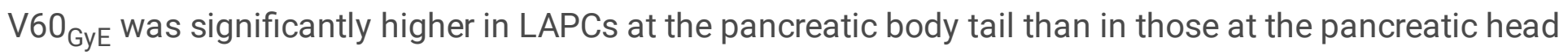
(66.8 vs. $50.0 \%, P<0.001$ ).

Table 3

Dose intensity based on the dose volume histogram for tumor location

\begin{tabular}{|c|c|c|c|c|}
\hline & & Head & Body-Tail & \\
\hline Parameter & & Median value (range) & Median value (range) & $P$ value \\
\hline \multirow[t]{5}{*}{ GTV } & Volume, cc & $39.2(7.9-88.9)$ & $49.2(9.1-141.0)$ & 0.038 \\
\hline & $\mathrm{V} 60_{\mathrm{GyE}}, \%$ & $50.0(6.2-98.7)$ & $66.8(25.2-99.7)$ & $<0.001$ \\
\hline & Dmax, GyE & $68.7(66.8-72.0)$ & $68.8(66.8-71.1)$ & 0.406 \\
\hline & Dmean, GyE & $58.8(48.8-66.4)$ & $61.4(50.7-67.3)$ & $<0.001$ \\
\hline & Dmin, GyE & $45.0(40.0-55.6)$ & $45.2(36.5-58.3)$ & 0.752 \\
\hline \multirow[t]{5}{*}{ CTV } & Volume, cc & $175.5(89.7-417.0)$ & $196.3(85.0-420.6)$ & 0.434 \\
\hline & $\mathrm{V} 60_{\mathrm{GyE}}, \%$ & $58.7(25.6-82.7)$ & $61.2(37.7-86.7)$ & 0.223 \\
\hline & Dmax, GyE & $69.7(67.7-72.7)$ & $69.7(68.0-71.7)$ & 0.285 \\
\hline & Dmean, GyE & $60.3(52.1-64.7)$ & $60.6(54.8-65.5)$ & 0.207 \\
\hline & Dmin, GyE & $44.3(31.6-47.6)$ & $44.4(38.2-50.2)$ & 0.697 \\
\hline \multirow[t]{5}{*}{ PTV } & Volume, cc & 340.1 (184.3-728.6) & $364.3(175.7-696.5)$ & 0.535 \\
\hline & $\mathrm{V} 60_{\mathrm{GyE}}, \%$ & $47.9(20.3-69.1)$ & $48.4(27.4-75.3)$ & 0.335 \\
\hline & Dmax, GyE & $69.9(67.7-72.7)$ & $69.8(68.0-72.2)$ & 0.192 \\
\hline & Dmean, GyE & $57.6(48.8-62.3)$ & $57.7(52.3-63.4)$ & 0.222 \\
\hline & Dmin, GyE & $37.2(23.0-41.4)$ & $37.4(28.5-45.1)$ & 0.208 \\
\hline
\end{tabular}

Abbreviations: GTV, gross tumor volume; CTV, clinical target volume; PTV, planning target volume; $\mathrm{GyE}$, Gy equivalents; $\mathrm{V}^{6} 0_{\mathrm{Gy}}$, the volume ratio irradiated over $60 \mathrm{GyE}$; Dmax, the maximum dose of the target volume; Dmean, the average dose of the target volume; Dmin, the minimum dose of the target volume.

Significant $P$ values $(<0.05)$ are in bold.

LAPCs without anterior peripancreatic invasion also had significantly longer MST than those with anterior peripancreatic invasion (28.1 [19.2-NA] vs. 17.4 [3.6-20.9] months, $P=0.024 ;$ Fig. 2c). Although there was no significant difference in the LPFS, the 1- and 2-year PFS rates were $55.8 \%$ (34.6-90.1) and 39.9\% (20.4-77.9) in LAPCs without anterior peripancreatic invasion, respectively, which were significantly higher than those with anterior peripancreatic invasion (34.6\% [26.0-46.1] and 15.8\% [9.2-27.4], 
respectively, $P=0.017$; Fig. $2 \mathrm{~d})$. LAPCs with anterior peripancreatic invasion had more peritoneal recurrence within 6 months than those without anterior peripancreatic invasion $(P=0.039$, Table 4$)$. The MSTs of the LAPCs at the pancreatic head and body-tail in combination with and without anterior peripancreatic invasion are summarized in Figure 3. LAPCs at the pancreatic body-tail without anterior peripancreatic invasion were associated with significantly longer OS than those with pancreatic head with and without anterior peripancreatic invasion or those at the pancreatic body-tail with anterior peripancreatic invasion (30.5 [24.4-NA] vs. 17.7 [13.9-21.4] months, $P=0.033$, Fig. 4).

Table 4 Recurrence pattern according to each clinical feature 
Anterior peripancreatic invasion
Tumor location

Positive Negative $P$ value Head Body- $P$ value

$(\mathrm{n}=\quad$ Tail $(\mathrm{n}$

59) =64)

0.275

Local progression, $\mathrm{n}(\%)$

0.555

$6(32)$

$13(68)$

No
$18 \quad 14(22)$

(31)

41

(69)

$50(78)$

Local progression within 6 months, n (\%)
Yes
7
No
7 (7)
$0(0)$
$3(5) \quad 4(6)$
(94)
$56 \quad 60(94)$
$\begin{array}{lll}97(93) & 19(100) & 56 \\ & & (95)\end{array}$
$\begin{array}{lll}97(93) & 19(100) & 56 \\ & & (95)\end{array}$

0.119

0.780

0.568

0.084

1 year, $\mathrm{n}(\%)$

Yes

No

$\begin{array}{lll}18 & 16(15) & 2(11) \\ (15) & 88(859 & 17(89) \\ 105 & & \end{array}$

(85)

$\begin{array}{ll}12 & 6(9) \\ (20) & 58(91) \\ 47 & \end{array}$

(80)

Distant metastasis, n (\%)

0.026

0.853

Yes

$74 \quad 67(64) \quad 7(37)$

No

(60)

49

(40)
37 (36)

$12(63)$
$36 \quad 38(59)$

(61)

23

(39)

Liver metastasis within 6 months, $\mathrm{n}$ (\%)

Yes

No

$\begin{array}{lll}23 & 22(21) & 1(5) \\ (19) & 82(79) & 18(95) \\ 100 & & \\ (81) & & \end{array}$

0.988

$\begin{array}{ll}11 & 12(19) \\ (19) & 52(81) \\ 48 & \end{array}$

(81)
Liver metastasis within 1 year, $\mathrm{n}(\%)$

Yes

No
Peritoneal dissemination within 6 months, $\mathrm{n}(\%)$

Yes

$\begin{array}{lll}30 & 28(27) & 2(11) \\ (24) & 76(73) & 17(89) \\ 99 & \end{array}$

(76) $\begin{array}{ll}14 & 16(25) \\ (24) & 48(75) \\ 45 & \end{array}$

(76)

\subsection{9}

$\begin{array}{lll}2 & 12(12) \quad 0(0)\end{array}$

$6(10) \quad 6(9)$ 
Peritoneal dissemination within 1 year, $\mathrm{n}(\%)$

No
Yes
(90)

0.584

$3(16)$
$16(84)$

$16(84)$

98

(80)
25
$(20)$
$82(79)$

$22(21)$

0.656

Significant $P$ values $(<0.05)$ are in bold.

\section{Discussion}

Controversies surrounding the optimal treatment strategy for LAPC exist. Many physicians consider that systemic chemotherapy is the sole effective treatment for LAPC; however, a considerable proportion of patients do not develop distant metastases, and local tumor progression is the only cause of death [9, 10]. GPT is an attractive treatment for LAPC without distant metastases because of its high potential for local tumor control [14]. In this study, we successfully reported high LPFS rates (1- and 2-year LPFS rates of $78.2 \%$ and $59.0 \%$, respectively) in patients with LAPC treated with GPT of $67.5 \mathrm{GyE}$; the MST was 18.7 months and the 1- and 2-year OS rates were $70.4 \%$ and $35.7 \%$, respectively. These values are comparable to those of intensive chemotherapies, such as FOLFIRINOX and GnP (MSTs, 24.2 and 18.8 months, respectively) [5, 6], photon radiotherapy with 50-54 GyE (MST, 9.6-17.6 months; 2-year OS rate, 10.528\%) [21-25], and proton radiotherapy with 50-67.5 GyE (MST, 18.4-25.6 months; 2-year OS rate, 3153\%) [15-18]. Long MST was achieved in patients with LAPC at the pancreatic body-tail and those with LAPC without anterior peripancreatic invasion (24.1 and 28.1 months, respectively), suggesting that GPT is a promising treatment option, especially for this subset of patients.

LAPCs at the pancreatic body-tail had a significantly higher GTV V60GyE than those at the pancreatic head $(66.8$ vs. $50.0 \%)$, as the irradiation doses were consistently restricted by the adjacent second and third portions of the duodenum in LAPCs at the pancreatic head. Similar to the well-known consequence that dose escalation improves OS and LPFS [17, 26, 27], OS and LPFS were better in patients with LAPC at the pancreatic body-tail than in those at the pancreatic head. However, even GTV V60GyE of LAPCs at the pancreatic body-tail was still insufficient for curative irradiation due to the restriction of irradiation doses to the adjacent $\mathrm{GI}$ tract. To further increase irradiation doses to the entire tumor volume, we developed a new conceptual approach called the space-making particle therapy, wherein we performed surgical spacer placement and subsequent PRT. Significant dose escalation by space-making particle therapy has been reported in LAPCs (mean GTV V60GyE, 66.4 to 84.7\%) [28], and the effect of this new technique on OS and LPFS is anticipated to be further elucidated in future studies.

LAPC often undergoes distant metastases, and the role of radiotherapy as systemic therapy may be limited. Our study demonstrated that GPT contributes to a high LPFS, albeit an insufficient PFS, suggesting that GPT provides feasible local tumor control but does not contribute to the control of distant 
metastases. Therefore, an optimal patient selection with a low risk of distant metastases is required to improve the survival outcomes of GPT. Our results also indicate that anterior peripancreatic invasion is a risk factor for peritoneal dissemination within 6 months. Furthermore, approximately $10-20 \%$ of patients with radiographically diagnosed LAPC have occult peritoneal dissemination $[29,30]$. Thus, exploratory laparoscopy before GPT may be recommended for LAPC with anterior peripancreatic invasion to exclude radiologically negative peritoneal dissemination cases. Other studies have reported that induction chemotherapy before chemoradiotherapy is also useful in excluding LAPC with occult metastases [3133]. A tailored treatment strategy based on the condition of each patient could achieve the better survival outcomes of LAPC.

In this study, the frequency of acute toxicities of $\geq$ grade $3(45 \%)$ was comparable to that in a previous report on chemotherapy concurrent with PRT (45\%) [19]. Although a direct comparison is difficult, GPT is a relatively safer treatment than FOLFIRINOX $(60 \%)$ and $\mathrm{GnP}(80 \%)[5,6]$. Moreover, GPT may be administered to patients who have difficulty receiving intensive chemotherapy owing to serious adverse events. However, late toxicities of $\geq$ grade 3 for the bile duct and GI tract should not be negligible. Based on our clinical experience, bile duct perforation is more likely to occur in patients with a metallic biliary stent, and we invariably use a plastic biliary stent. Additionally, we used a proton pump inhibitor and mucosal protective agent without failing to prevent peptic ulcer diseases.

This study had some limitations. This study was a small retrospective non-randomized study at a single institution, and our patient population might have been biased toward favoring the effectiveness of GPT. Moreover, adjuvant treatment after GPT was not performed in our institution, and there were insufficient data on the clinical course after GPT. A multi-institutional prospective study would reduce the possibility of bias and provide a more conclusive result on the factors associated with long-term survival outcomes of GPT for LAPC.

\section{Conclusions}

Patients with LAPC at the pancreatic body-tail and those with LAPC without anterior peripancreatic invasion showed favorable OS after GPT. With appropriate patient selection based on the accessibility of irradiation and the risk of metastases, GPT would aid in the achievement of better survival outcomes, thus showing a promising potential as a treatment option for LAPC.

\section{Abbreviations}

$\mathrm{Cl}$, confidence interval; CT, computed tomography; CTV, clinical target volume; FDG-PET, positron emission tomography with 18F-fluorodeoxyglucose; FOLFIRINOX, 5-fluorouracil, leucovorin, irinotecan, and oxaliplatin; GI, gastrointestinal; GnP, gemcitabine plus nab-paclitaxel; GPT, gemcitabine-concurrent proton radiotherapy; GTV, gross tumor volume; GyE, Gy equivalents; HR, hazard ratio; LAPC, locally advanced pancreatic cancer; LPFS, local progression-free survival; MST, median survival time; NA, not available; OS, 
overall survival; PFS, progression-free survival; PRT, particle radiotherapy; PTV, planning target volume; $\mathrm{RBE}$, relative biological effectiveness; $\mathrm{V} 60_{\mathrm{GyE}}$, the volume ratio irradiated over $60 \mathrm{GyE}$.

\section{Declarations}

\section{Ethics approval and consent to participate}

This study was approved by the Institutional Review Board of Hyogo lon Beam Medical Center and conducted according to the ethical standards stated in the 1964 Declaration of Helsinki and its later amendments; the need for informed consent was waived owing to the retrospective nature of the study.

\section{Consent for publication}

Not applicable in this section.

\section{Availability of data and materials}

The datasets used and analyzed during the current study are available from the corresponding author on reasonable request.

\section{Competing interests}

The authors declare that they have no competing interests.

\section{Funding}

This research did not receive any specific grant from funding agencies in the public, commercial, or notfor-profit sectors.

\section{Authors' contributions}

Study concept and design: YO and KT. Data acquisition: YO. Quality control of data: KT, SP, MS, DT, YM, NS, ST and TO. Data analysis and interpretation: YO and KT. Statistical analysis: YO and SP. Manuscript preparation: YO. Manuscript editing: KT and YN. Manuscript review: HT and TF. All authors read and approved the final manuscript.

\section{Acknowledgements}

The authors thank all staff of the Hyogo Ion Beam Medical Center for their efforts for GPT.

\section{Authors' information}

aDepartment of Surgery, Division of Hepato-Biliary-Pancreatic Surgery, Kobe University Graduate School of Medicine, Kobe, Hyogo, Japan 
${ }^{\mathrm{b}}$ Department of Radiology, Hyogo Ion Beam Medical Center, Tatsuno, Hyogo, Japan

'Department of Radiation Physics, Hyogo Ion Beam Medical Center, Tatsuno, Hyogo, Japan

\section{References}

1. Carioli G, Bertuccio P, Boffetta P, Levi F, La Vecchia C, Negri E, et al. European cancer mortality predictions for the year 2020 with a focus on prostate cancer. Ann Oncol. 2020;31:650-8.

2. Siegel RL, Miller KD, Jemal A. Cancer statistics, 2020. CA Cancer J Clin. 2020;70:7-30.

3. Mizrahi JD, Surana R, Valle JW, Shroff RT. Pancreatic cancer. Lancet. 2020;395:2008-20.

4. Tempero MA, Malafa MP, Al-Hawary M, Behrman SW, Benson III AB, Cardin DB, et al. Pancreatic Adenocarcinoma, Version 2.2021, NCCN Clinical Practice Guidelines in Oncology. J Natl Compr Canc Netw. 2021;19:439-57.

5. Suker M, Beumer BR, Sadot E, Marthey L, Faris JE, Mellon EA, et al. FOLFIRINOX for locally advanced pancreatic cancer: a systematic review and patient-level meta-analysis. Lancet Oncol. 2016;17:80110.

6. Philip PA, Lacy J, Portales F, Sobrero A, Pazo-Cid R, Manzano Mozo JL, et al. Nab-paclitaxel plus gemcitabine in patients with locally advanced pancreatic cancer (LAPACT): a multicentre, open-label phase 2 study. Lancet Gastroenterol Hepatol. 2020;5:285-94.

7. Loehrer Sr PJ, Feng Y, Cardenes H, Wagner L, Brell JM, Cella D, et al. Gemcitabine alone versus gemcitabine plus radiotherapy in patients with locally advanced pancreatic cancer: an Eastern Cooperative Oncology Group trial. J Clin Oncol. 2011;29:4105-12.

8. Hammel P, Huguet F, van Laethem JL, Goldstein D, Glimelius B, Artru P, et al. Effect of chemoradiotherapy vs chemotherapy on survival in patients with locally advanced pancreatic cancer controlled after 4 months of gemcitabine with or without erlotinib: the LAP07 randomized clinical trial. JAMA. 2016;315:1844-53.

9. lacobuzio-Donahue CA, Fu B, Yachida S, Luo M, Abe H, Henderson CM, et al. DPC4 gene status of the primary carcinoma correlates with patterns of failure in patients with pancreatic cancer. J Clin Oncol. 2009;27:1806-13.

10. Peixoto RD, Speers C, McGahan CE, Renouf DJ, Schaeffer DF, Kennecke HF. Prognostic factors and sites of metastasis in unresectable locally advanced pancreatic cancer. Cancer Med. 2015;4:1171-7.

11. Thompson RF, Mayekar SU, Zhai H, Both S, Apisarnthanarax S, Metz JM, et al. A dosimetric comparison of proton and photon therapy in unresectable cancers of the head of pancreas. Med Phys. 2014;41:10.081711.

12. Ling TC, Slater JM, Mifflin R, Nookala P, Grove R, Ly AM, et al. Evaluation of normal tissue exposure in patients receiving radiotherapy for pancreatic cancer based on RTOG 0848. J Gastrointest Oncol. 2015;6:108-14. 
13. Greco C, Wolden S. Current status of radiotherapy with proton and light ion beams. Cancer. 2007;109:1227-38.

14. Terashima K, Demizu Y, Hashimoto N, Jin D, Mima M, Fujii O, et al. A phase I/II study of gemcitabineconcurrent proton radiotherapy for locally advanced pancreatic cancer without distant metastasis. Radiother Oncol. 2012;103:25-31.

15. Sachsman S, Nichols RC, Morris CG, Zaiden R, Johnson EA, Awad Z, et al. Proton therapy and concomitant capecitabine for non-metastatic unresectable pancreatic adenocarcinoma. Int J Part Ther. 2014;1:692-701.

16. Maemura K, Mataki Y, Kurahara H, Kawasaki Y, lino S, Sakoda M, et al. Comparison of proton beam radiotherapy and hyper-fractionated accelerated chemoradiotherapy for locally advanced pancreatic cancer. Pancreatology. 2017;17:833-8.

17. Shinoto $M$, Terashima K, Suefuji $H$, Matsunobu A, Toyama S, Fukunishi K, et al. A single institutional experience of combined carbon-ion radiotherapy and chemotherapy for unresectable locally advanced pancreatic cancer. Radiother Oncol. 2018;129:333-9.

18. Hiroshima Y, Fukumitsu N, Saito T, Numajiri H, Murofushi KN, Ohnishi K, et al. Concurrent chemoradiotherapy using proton beams for unresectable locally advanced pancreatic cancer. Radiother Oncol. 2019;136:37-43.

19. Al-Hawary MM, Francis IR, Chari ST, Fishman EK, Hough DM, Lu DS, et al. Pancreatic ductal adenocarcinoma radiology reporting template: consensus statement of the Society of Abdominal Radiology and the American Pancreatic Association. Radiology. 2014;270:248-60.

20. Kagawa K, Murakami M, Hishikawa Y, Abe M, Akagi T, Yanou T, et al. Preclinical biological assessment of proton and carbon ion beams at Hyogo Ion Beam Medical Center. Int J Radiat Oncol Biol Phys. 2002;54:928-38.

21. Shinchi H, Maemura K, Mataki Y, Kurahara H, Sakoda M, Ueno S, et al. A phase Il study of oral S-1 with concurrent radiotherapy followed by chemotherapy with S-1 alone for locally advanced pancreatic cancer. J Hepatobiliary Pancreat Sci. 2012;19:152-8.

22. Ikeda M, loka T, Ito $\mathrm{Y}$, Yonemoto $\mathrm{N}$, Nagase $\mathrm{M}$, Yamao K, et al. A multicenter Phase II trial of S-1 with concurrent radiation therapy for locally advanced pancreatic cancer. Int J Radiat Oncol Biol Phys. 2013;85:163-9.

23. Ducreux M, Giovannini M, Baey C, Llacer C, Bennouna J, Adenis A, et al. Radiation plus docetaxel and cisplatin in locally advanced pancreatic carcinoma: A non-comparative randomized phase II trial. Dig Liver Dis. 2014;46:950-5.

24. Fiore M, Trodella L, Valeri S, Borzomati D, Floreno B, Ippolito E, et al. Prospective study of cetuximab and gemcitabine in combination with radiation therapy: feasibility and efficacy in locally advanced pancreatic head cancer. Radiat Oncol. 2015;10:255.

25. Hurt CN, Falk S, Crosby T, McDonald A, Ray R, Joseph G, et al. Long-term results and recurrence patterns from SCALOP: a phase II randomised trial of gemcitabine- or capecitabine-based chemoradiation for locally advanced pancreatic cancer. Br J Cancer. 2017;116:1264-70. 
26. Krishnan S, Chadha AS, Suh Y, Chen HC, Rao A, Das P, et al. Focal radiation therapy dose escalation improves overall survival in locally advanced pancreatic cancer patients receiving induction chemotherapy and consolidative chemoradiation. Int J Radiat Oncol Biol Phys. 2016;94:755-65.

27. Kawashiro S, Yamada S, Okamoto M, Ohno T, Nakano T, Shinoto M, et al. Multi-institutional study of carbon-ion radiotherapy for locally advanced pancreatic cancer: Japan carbon-ion radiation oncology study group (J-CROS) Study 1403 pancreas. Int J Radiat Oncol Biol Phys. 2018;101:121221.

28. Lee D, Komatsu S, Terashima K, Toyama H, Matsuo Y, Takahashi D, et al. Surgical spacer placement for proton radiotherapy in locally advanced pancreatic body and tail cancers: initial clinical results. Radiat Oncol. 2021;16:3.

29. Satoi S, Yanagimoto H, Yamamoto T, Toyokawa H, Hirooka S, Yamaki S, et al. A clinical role of staging laparoscopy in patients with radiographically defined locally advanced pancreatic ductal adenocarcinoma. World J Surg Oncol. 2016;14:14.

30. Suker M, Koerkamp BG, Coene PP, van der Harst E, Bonsing BA, Vahrmeijer AL, et al. Yield of staging laparoscopy before treatment of locally advanced pancreatic cancer to detect occult metastases. Eur J Surg Oncol. 2019;45:1906-11.

31. Mahadevan A, Miksad R, Goldstein M, Sullivan R, Bullock A, Buchbinder E, et al. Induction gemcitabine and stereotactic body radiotherapy for locally advanced nonmetastatic pancreas cancer. Int J Radiat Oncol Biol Phys. 2011;81:e615-22.

32. Kim JS, Lim JH, Kim JH, Im SA, Chie EK, Hwang JH, et al. Phase II clinical trial of induction chemotherapy with fixed dose rate gemcitabine and cisplatin followed by concurrent chemoradiotherapy with capecitabine for locally advanced pancreatic cancer. Cancer Chemother Pharmacol. 2012;70:381-9.

33. Mukherjee S, Hurt CN, Bridgewater J, Falk S, Cummins S, Wasan H, et al. Gemcitabine-based or capecitabine-based chemoradiotherapy for locally advanced pancreatic cancer (SCALOP): a multicentre, randomised, phase 2 trial. Lancet Oncol. 2013;14:317-26.

\section{Figures}
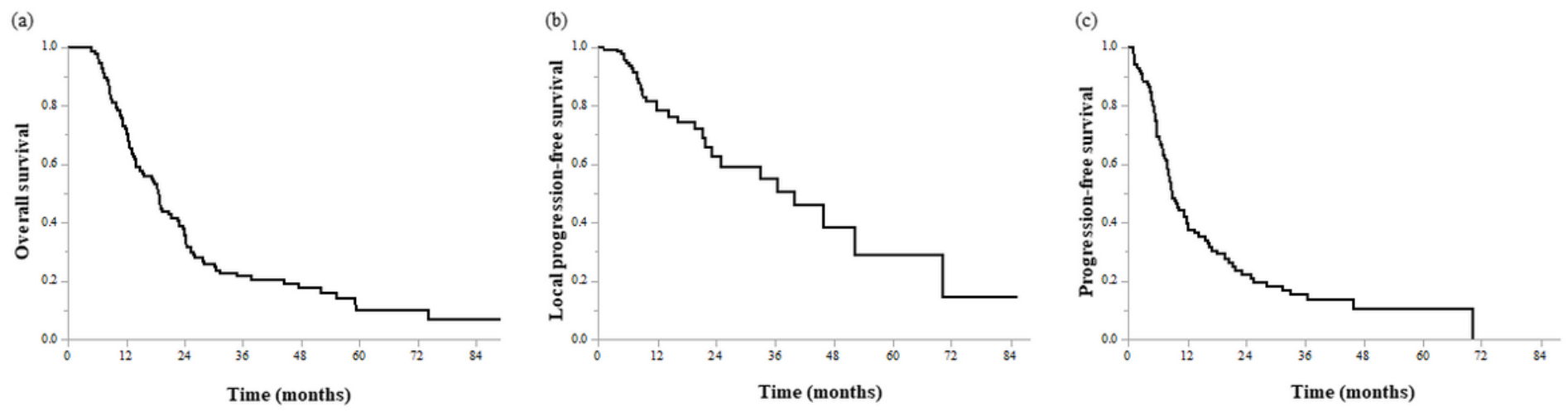
Figure 1

Survival curves for all patients. (a) Overall survival, (b) local progression-free survival, and (c) progression-free survival.

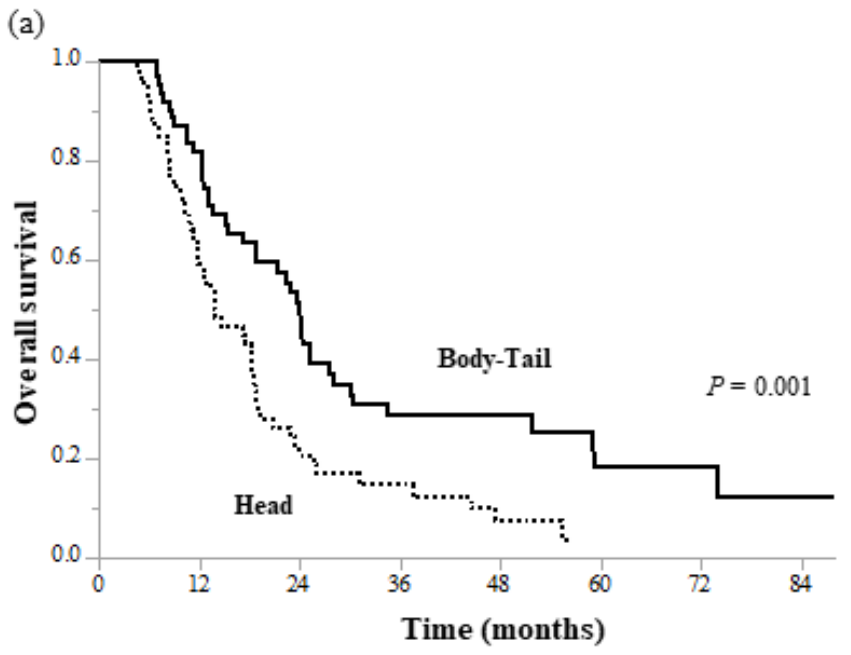

(c)

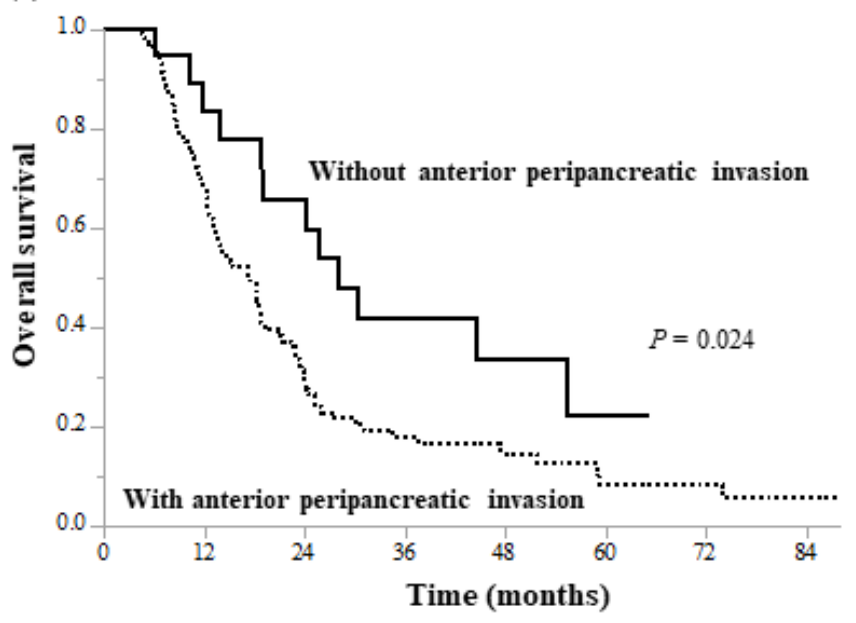

(b)

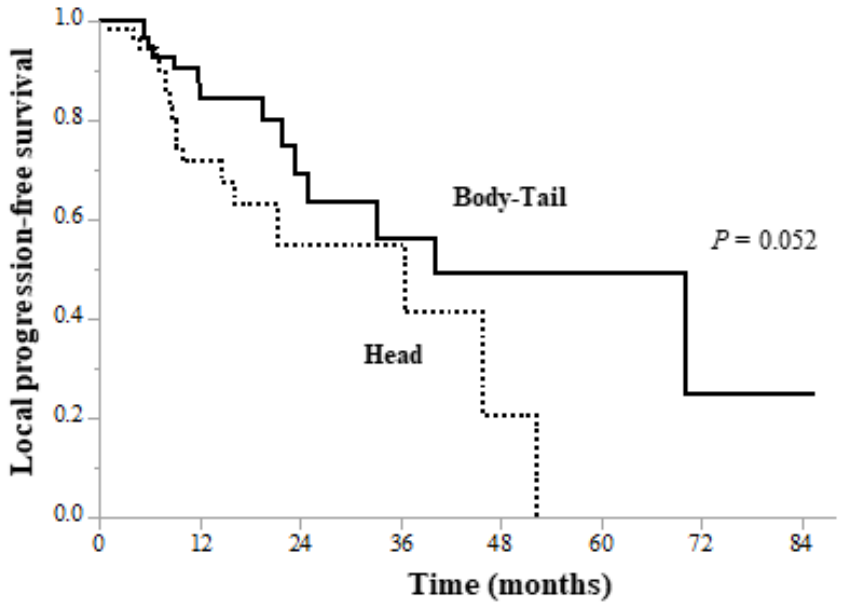

(d)

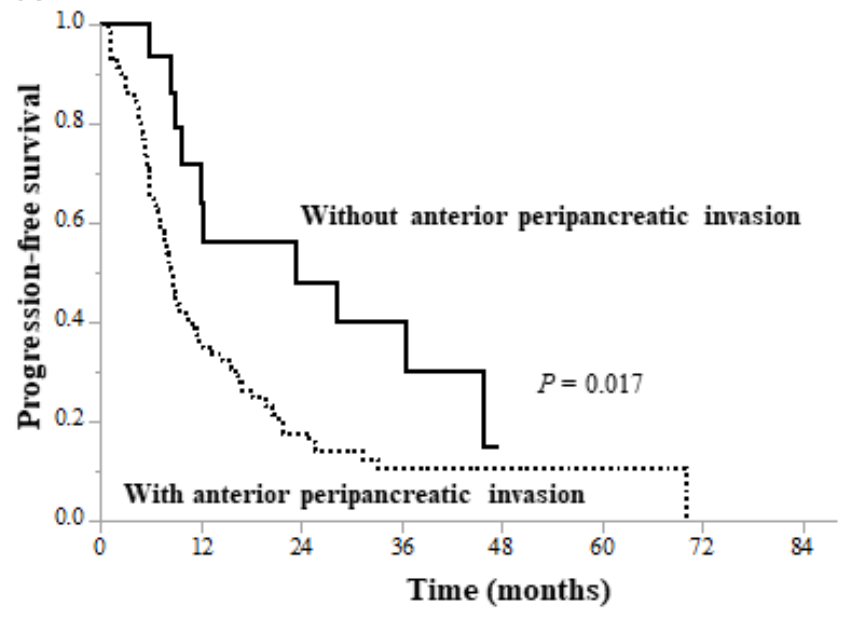

Figure 2

Survival curves for subsets of patients. Overall survival (a) and local progression-free survival (b) curves of patients with locally advanced pancreatic cancer (LAPC) at the pancreatic head and body-tail. Overall survival (c) and progression-free survival (d) curves of patients with LAPC with and without anterior peripancreatic invasion. 


\begin{tabular}{|c|c|c|}
\hline & \multicolumn{2}{|c|}{ Anterior peripancreatic invasion } \\
\hline & $\begin{array}{c}\text { Negative }(n=19) \\
\text { MST: } 28.1 \text { months }(19.2-\mathrm{NA})\end{array}$ & $\begin{array}{c}\text { Positive }(n=104) \\
\text { MST: } 17.4 \text { months }(3.6-20.9)\end{array}$ \\
\hline $\begin{array}{c}\text { Body-Tail }(n=64) \\
\text { MST: } 24.1 \text { months }(18.8-30.2)\end{array}$ & $\begin{array}{c}n=8 \\
\text { MST: } 30.5 \text { months (24.4-NA) }\end{array}$ & $\begin{array}{c}n=56 \\
\text { MST: } 22.9 \text { months }(15.6-27.7)\end{array}$ \\
\hline $\begin{array}{c}\text { Head }(n=59) \\
\text { MST: } 14.0 \text { months }(12.1-18.9)\end{array}$ & $\begin{array}{c}n=11 \\
\text { MST: } 25.9 \text { months (13.9-NA) }\end{array}$ & $\begin{array}{c}n=48 \\
\text { MST: } 13.6 \text { months }(11.2-18.5)\end{array}$ \\
\hline
\end{tabular}

Figure 3

Median survival times of patients with locally advanced pancreatic cancers at the pancreatic head and body-tail in combination with and without anterior peripancreatic invasion.

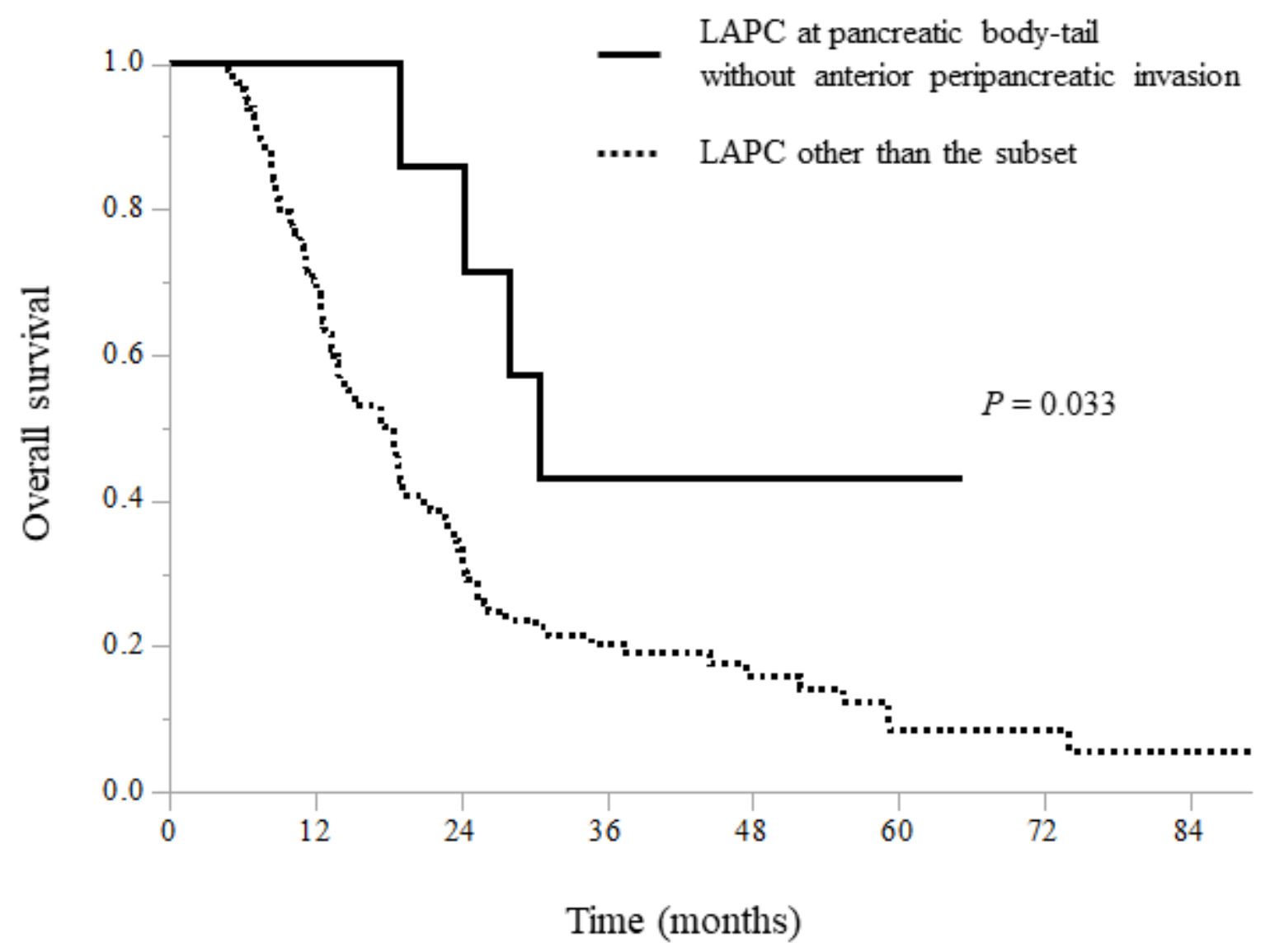

Figure 4

Comparison of overall survival curves between patients with locally advanced pancreatic cancer (LAPC) at the pancreatic body-tail without anterior peripancreatic invasion and those with LAPC other than the 
subset.

Page 22/22 